\title{
Medical Refuseniks in the Soviet Union and Their Patients
}

Paul Robinson, Consultant and Senior Lecturer, Department of Psychological Medicine, King's College Hospital, London SE5 and MARK Berger, Fellow in Hematology and Oncology, Hospital of the University of Pennsylvania, Philadelphia, USA

In July 1986 we went to Moscow and Leningrad to visit refusenik physicians and to learn about the medical and psychiatric problems of this community. Refuseniks, the several thousand Soviet Jews who have applied for-and been refused-permission to go to Israel, suffer considerable official and unofficial punishment. We were interested in the effects of this treatment on physical and mental health as well as in the experiences of Soviet Jewish physicians who apply for emigration. Our information comes from discussions with a number of doctors in both Moscow and Leningrad who gave us examples from their own experiences and those of their patients.

Career suppression in refusenik physicians

We encountered several physicians who, as a direct result of applying for emigration, had lost their jobs. Unemployment entails the risk of being imprisoned for the 'crime' of parasitism and the incentive to take any available job is very strong. For example, Igor Uspensky, formerly a senior scientist at the Moscow Institute of Medical Parasitology studying the biology of blood-sucking arthropods, now works as a lift operator, the best job he could obtain. Talented researchers have been prevented from pursuing further research and have found their careers suppressed and curtailed.

\section{Illnesses observed in refuseniks}

Apparently related to political status. The medical and psychiatric morbidity of refusenik status is difficult to study. However, we observed in several individuals illnesses that seemed at least partly related to political status. A history of depression following the receipt of a refusal was common, as were peptic ulcers. Recently, Dr Lev Goldfarb, a physician who spent many years working as medical adviser to the refusenik community in Moscow and who now works at the National Institute of Health in Washington DC, reported a high incidence among refuseniks of illnesses thought to be associated with psycho-social stress such as irritable bowel syndrome, peptic ulcer, migraine, hypertension and myocardial infarction as well as anxiety and depression ${ }^{1}$ and our experiences accord with his observations.

Dr Elizabeth Raben, a neurologist, (who encouraged us to disclose her identity and clinical history in the hope that it might help her situation) was one of the most severely disabled people we met. She speaks no English but her husband, Anatoly Raben, a former professor of dermatology, acted as interpreter. As a young woman she had endured the murder of her brother-in-law by Stalin and the incarceration of her husband for four years in a labour camp in the 1950s without suffering psychiatric illness. In 1979 she and her husband applied for an exit visa for Israel. The negative reply took almost three years to come. Both resigned their hospital posts, being aware that dismissal after visa application was inevitable and was often accompanied by harassment of colleagues at work. Their resignations avoided the latter.

As a result of her unemployment she became much closer to her aged mother who died in 1984 . She began to lose weight, from a premorbid weight of $70 \mathrm{Kg}$ to $45 \mathrm{Kg}$ over a few months. Cancer was suspected and full investigations performed, including brain CT scan-a very difficult procedure to obtain for all but the best connected. All these proved negative and three psychiatrists were consulted. She was given, in turn, low doses of a tricyclic antidepressant, a neuroleptic and a benzodiazepine.

One of us (PR) was asked by one of the refuseniks who coordinate medical care for their community to see her as a 'fourth opinion'. The interview was conducted in their comfortable Moscow flat. She was an emaciated lady with depressive posture and facies who described a classical picture-low mood, morning worsening, poor self image, rumination, mostly depressive but containing some optimistic thoughts about being allowed to emigrate to Israeland total loss of interest in her previous activities. She was often left alone during the day while the rest of her family went about its business.

After the two hour interview, it appeared that she was suffering from a depressive illness related to her political status, to her mother's death and to the loss of her job. Treatment recommended was imipramine at $150 \mathrm{mg}$ daily and the family was encouraged to spend more time with her and to help her to put on weight. Since our visit the couple and one of their two daughters have been allowed to leave the Soviet Union, and a clinical evaluation in December 1987, 17 months after our first meeting, revealed a marked improvement in her mood, although she was still preoccupied and distressed by the refusal of the visa authorities to allow their other daughter, Helen Raben, a lawyer , and her family, to leave the Soviet Union. 
Depression often followed refusal of an application for an exit visa. We met another refusenik, Dr Boris Konnikov, who was an accomplished neurologist studying animal models of epilepsy when he and his wife applied for exit visas. He was demoted to a non-research post reading EEGs. His wife became depressed and lost $20 \mathrm{~kg}$ in weight, recovering after about a year of psychiatric treatment.

In the case of Iosef Zaretsky, a chronic peptic ulcer was kept under control using cimetidine (not freely available in the Soviet Union and obtained only with great difficulty) but he suffered clear exacerbations with each refusal of a visa. He had been, prior to his visa application, a research oncologist. He applied to leave, together with his family, in 1978. His mother, sister and grandfather emigrated to Israel in 1980, but he, his wife and daughter were refused permission to leave, because of a relative's alleged access to 'State secrets'. His sister and grandfather have since died. $\mathrm{He}$ had been engaged in research at the prestigious Ivanovsky Institute of Virology in Moscow, and in 1977 he concluded a contract to publish his thesis The Molecular Biology of Oncogenic Viruses. However, as soon as he applied for emigration the book was suppressed, he was forced to resign his post and he and his wife, a neurologist, spent the next four years unemployed, risking imprisonment for 'parasitism'.

Eventually he was given a job as a physician in an outpatient urology clinic and now he accepts that his research, now ten years out of date, will never be published. In March 1987, following publicity in the Western medical press, ${ }^{2}$ he finally received an exit visa and he is now attempting to reconstruct his research career in Tel Aviv University.

A Leningrad neurologist, Leonid Raskin, described severe depression and marital breakdown shortly after being refused a visa. However, by immersing himself in professional and cultural activity with other refuseniks, he established a social network which allowed him to recover from depression to some extent.

Political status complicating the course of physical disease. We met some refuseniks who had developed serious illnesses which were complicated by their political status, although not caused by it. For instance, Tanya B, 37 years old, developed breast cancer in December 1985 and had a mastectomy. When we visited she was coming to the end of six months of adjuvant chemotherapy. One reaction to her illness was to try to take advantage of her misfortune to embarrass the authorities into allowing her to leave. She formed a Refuseniks Cancer Patients Committee, held a press conference for Western journalists in her Moscow flat, and thereby disseminated information on her group to the West. She and her husband, who waited 20 years for an exit visa, were, after this publicity, allowed to leave. Furthermore, another member of her group, Inna Meiman, was allowed to travel to the United States for treatment of her sarcoma. Unfortunately she died from her tumour several months later, while separated from her husband, prominent human rights activist and mathematician Naum Meiman. (He is still in the Soviet Union awaiting an exit visa).
Pressure from the West appeared to result in a softening of the Soviet attitude towards these patients.

\section{Lack of morbidity in children}

We were surprised to learn of the apparent rarity of psychiatric disturbance amongst the children of refuseniks. They are certainly subjected to considerable abuse. At school, when a child's family has applied for a visa, other pupils in his class are required to recite condemnation of him-to brand him a traitor and a number of children, after encouragement of their classmates by teachers, have been beaten up. At least one child has died as a result of this. ${ }^{1}$ Lesser harassment is experienced frequently. The child of one refusenik we met was expelled from his school after he had been observed outside a Moscow synagogue during a Jewish holiday celebration. Getting him into another school was achieved only with great difficulty.

One child psychiatrist, also a refusenik, Valery Abramovitch, said that he was not aware of serious psychiatric morbidity among the children. It may be that such disorders that exist are dealt with or concealed by the family without recourse to child psychiatry which is, in the Soviet Union, more concerned with organic disorders than with the emotional and conduct disorders familiar to Western child psychiatrists. However, the intense support provided by the refusenik social network may well act as a protective influence which could account, in part, for the apparent lack of childhood disorder.

\section{Adaptive response to refusenik status}

The strength of an individual's social network has been found to predict psychiatric illness, ${ }^{3}$ and we met a number of refuseniks whose ability to cope with adverse circumstances was enhanced by their involvement in social, professional, political and religious activities for the refusenik community, including arranging medical care, bringing Western visitors to see refusenik families, or engaging in clandestine religious activity such as celebration of religious festivals and Hebrew teaching (for which a number of refuseniks have been imprisoned). Thus, long-term refuseniks often participate in a culturally defined network of social activities which replaces the contacts with wider Soviet society from which they are largely excluded.

We saw a number of refuseniks who threw themselves into political or religious life and seemed thereby to protect themselves against the despair that we encountered and heard about in others. Some physicians such as Lev Goldfarb and, more recently Iosef Zaretsky, organised refusenik physicians to care for other refuseniks. Although polyclinic doctors are available to refuseniks as they are to all Soviet citizens, they are treated with suspicion, and sometimes a polyclinic doctor becomes hostile upon learning of the family's political status. Physicians who are also refuseniks are greatly preferred, both to give medical advice and help obtain scarce medications for their patients. We met one refusenik doctor in Leningrad who, with the acquiescence of the non-Jewish staff at the clinic, slips Jewish patients from outside her catchment area into her list 
if she has not seen the 40 patients in a day that is required by her 'plan'.

Attempts to pursue academic activity, in spite of official repression, also serve to improve morale as well as helping refusenik physicians and scientists keep up to date. Medical seminars had been organised regularly by Dr Goldfarb but since his departure they have become more difficult to arrange. One of the authors (PR) was asked to speak to a group of refusenik physicians. This seminar took place in the living room of a refusenik's small flat in Moscow. A very old slide projector was found and a lecture given on the role of gastric function in satiety. The discussion was lively and compared favourable with comments and questions after a similar talk given at a conference in New York, one month before. By means of such seminars the medical refuseniks, prohibited from pursuing their own research interests, are able to have some contact with medical researchers. An abstract of the seminar given in Moscow has been submitted to a new journal dedicated to reporting the academic activities, many clandestine, that are organised by the refuseniks. ${ }^{4}$

\section{Discussion}

Little previous information has emerged on the health of people held in the Soviet Union awaiting exit visas. We found indications that this form of political repression is associated with both psychiatric and physical morbidity. However, our information is anecdotal and there is a need for a more formal assessment of the epidemiology of the problem. Our impression was that illness on receiving a refusal was common, and that support provided by the very close-knit community was an important way of coping with persecution and ostracism that often followed a visa application. A study of the extent and nature of this morbidity would require a comprehensive survey, perhaps organised by the refusenik physicians themselves.

Soviet refusenik physicians are often subjected to disruption of their professional development as soon as they apply to emigrate. They usually lose their jobs, and researchers are denied the opportunity to continue their studies or publish work already completed. This treatment cannot be construed as other than punishment for submitting a visa application, the refusal of which prevents these doctors from leaving the country to pursue their research elsewhere. This abuse continues during the present era of supposed liberalisation. It is our view that treatment of medical refuseniks might improve if colleagues in the West expressed their disapproval and concern to the Soviet medical establishment.

\section{REFERENCES}

'GoLDFARB, L. (1986) Address to workshop 'The psychology of being a refusenik', Oxford, 23 November 1986.

${ }^{2}$ Robinson, P. H. \& Berger, M. (1986) Soviet physicians denied exist visas. Lancet, ii, 690.

${ }^{3}$ Brown, G. W., Bhrolchain, M. N. \& Harris, T. (1975) Social class and psychiatric disturbance among women in an urban population. Sociology, 9, 225-254.

${ }^{4}$ RoBrnson, P. H. Gastric function and satiety. Journal of the Academic Proceedings of Soviet Jewry. (Submitted).

\section{The Gower's Prize}

The Gower's Prize is awarded biennially by the council of the International League Against Epilepsy (British Branch) for the best dissertation on any topic related to epilepsy of not more than $\mathbf{5 0 0 0}$ words presented in English. Entries can be accepted from anywhere in the world providing they are in English. There are three sections to the Gower's Prize:

1. The Young Physicians Prize of $£ 250$, limited to young qualified doctors under the age of 35 at the time they submit their dissertation.

2. The Medical Students Prize of $£ 100$ each. One for a dissertation on epilepsy, the other for the best case history of a patient or patients with epilepsy personally seen by the medical student. This part of the competition is open to bona fide medical students of any university and includes those students qualifying in the years 1987-88
3. The Health Professionals Prize of $£ 100$, awarded for the best dissertation submitted by any bona fide health professional, trainee health professional in any discipline related to epilepsy.

In all three categories runner-up prizes may be awarded if of sufficient merit. Typed entries should be submitted by 1 June 1988. Details of the entrant's name and address and place of work should be submitted separately with the entry so that the judges of the competition will not be aware of where the entries have come from. Prizes will only be awarded if they are deemed to be of sufficient merit and prize winners will be invited to the British/Danish/Dutch biennial symposium on epilepsy to be held near Amsterdam in September 1988.

Entries should be sent to Dr T. A. Betts, Neurophysiology Unit, Aston University, Aston Triangle, Birmingham, B4 7ET. 